\title{
Poor adherence with inhaled corticosteroids for asthma: can using a single inhaler containing budesonide and formoterol help?
}

\author{
Milind P Sovani, Christopher I Whale, Janet Oborne, Sue Cooper, \\ Kevin Mortimer, Tommy Ekström, Anne E Tattersfield, and Timothy W Harrison
}

\author{
ABSTRACT \\ Background \\ Poor adherence with inhaled corticosteroids is an \\ important problem in asthma management. Previous \\ approaches to improving adherence have had \\ limited success. \\ Aim \\ To determine whether treatment with a single inhaler \\ containing a long-acting $\beta_{2}$-agonist and a \\ corticosteroid for maintenance treatment and symptom \\ relief can overcome the problem of poor adherence \\ with inhaled corticosteroids. \\ Design of study \\ Randomised, parallel group, open-label trial. \\ Setting \\ Forty-four general practices in Nottinghamshire. \\ Method \\ Participants who used less than $70 \%$ of their \\ prescribed dose of inhaled corticosteroid and had \\ poorly controlled asthma were randomised to \\ budesonide $200 \mu \mathrm{g}$ one puff twice daily plus their own \\ short-acting $\beta_{2}$-agonist as required (control group), or \\ budesonide/formoterol 200/6 $\mu \mathrm{g}$ one puff once daily \\ and as required (active group) for 6 months. The \\ primary outcome was inhaled corticosteroid dose. \\ Results \\ Seventy-one participants ( 35 control, 36 active group) \\ were randomised. Adherence with budesonide in the \\ control group was approximately $60 \%$ of the prescribed \\ dose. Participants in the active group used \\ approximately $80 \%$ more budesonide than participants \\ in the control group (448 versus $252 \mu \mathrm{g} /$ day, mean \\ difference $196 \mu \mathrm{g}$, 95\% confidence interval 113 to 279 ; \\ $P<0.001)$ and were less likely to withdraw from the study \\ ( 3 versus $13 ; P<0.01$ ). No safety issues were identified. \\ Conclusion \\ Using a single inhaler for both maintenance treatment \\ and symptom relief approximately doubled the dose of \\ inhaled corticosteroid taken, suggesting this could be a \\ useful strategy to overcome the problems related to \\ poor adherence with inhaled corticosteroids. \\ Keywords \\ asthma; budesonide; formoterol; inhaled \\ corticosteroids; patient-non-adherence.
}

\section{INTRODUCTION}

Poor adherence with inhaled corticosteroids is a major problem in asthma management, ${ }^{1-3}$ occurring in $30-60 \%$ of patients. ${ }^{4-6}$ Reasons for poor adherence are numerous, but include a dislike of inhaled corticosteroids, lack of rapid symptom relief, and complicated treatment regimens. ${ }^{7-9}$

Because the $\beta_{2}$-agonist formoterol has a rapid onset and long duration of action, ${ }^{10}$ it can be used for symptom relief and maintenance treatment. ${ }^{11-13}$ When combined with budesonide in a single inhaler and used in this way it simplifies asthma treatment and provides a dose of inhaled corticosteroid with every dose of relief medication. Recent large multicentre studies show that this single-inhaler approach improves asthma control compared with a higher dose of inhaled corticosteroid,,${ }^{14-16}$ or an equivalent or higher dose of a combined long-acting $\beta_{2}$-agonist and corticosteroid used for maintenance treatment only. ${ }^{16-19}$ The same approach may be particularly useful in patients who have poor adherence with inhaled corticosteroids because they would be

MP Sovani, DM, research fellow; CI Whale, MRCP, research fellow; J Oborne, BSc, research fellow; S Cooper, $M S c$, research fellow; K Mortimer, $P h D$, research fellow; AE Tattersfield, MD, professor of respiratory medicine, Division of Respiratory Medicine, University of Nottingham, Nottingham City Hospital. T Ekström, MD, head of clinical research department, AstraZeneca, Sweden. TW Harrison, $M D$, consultant respiratory physician, Nottingham City Hospital NHS Trust, Nottingham.

Address for correspondence

Milind P Sovani, Respiratory Medicine, Queens Medical Centre Nottingham, Derby Road, Nottingham NG7 2UH. E-mail: sovani6@aol.com

Submitted: 9 July 2007; Editor's response: 14 August 2007; final acceptance: 16 October 2007.

(C)British Journal of General Practice 2008; 58: 37-43.

DOI: 10.3399/bjgp08X263802 
unable to use a $\beta_{2}$-agonist without taking an inhaled corticosteroid at the same time. For these patients the aim would be to increase the dose of inhaled corticosteroid taken.

This research was a pragmatic, parallel group, feasibility study to determine whether the underuse of inhaled corticosteroids by patients who are poorly adherent could be overcome by using a single inhaler containing budesonide and formoterol once daily and as required. The study had to be open-label as the specific focus of the study was to determine the effects of patients having only one inhaler, and a double-blind study would have required a doubledummy design and, therefore, two inhalers. Interventions during the study were limited to minimise the effect that being in the study had on patient adherence.

\section{METHOD}

\section{Participants}

General practices in Nottinghamshire were asked to participate if patient records had been stored for at least a year on an accessible database (Torex, EMIS or Micro Medic). Suitable patients were identified using a stepwise approach combining computerised general practice records and interviews (Figure 1).

The study recruited patients aged 18-70 years with a diagnosis of asthma and currently prescribed $400-1000 \mu \mathrm{g} /$ day of beclometasone dipropionate or equivalent. Participants had to have evidence of poor adherence, which was defined as having collected less than $70 \%$ of the expected number of prescriptions for inhaled corticosteroid in the year prior to the study. They also had to have evidence of poor asthma control which was defined as: having prescriptions for at least two courses of prednisolone or 10 canisters of short-acting $\beta_{2}$-agonist in the year prior to the study; and taking four or more rescue puffs of $\beta_{2}$-agonist for at least 4 days a week over the previous 4 weeks.

Exclusion criteria included the use of a long-acting $\beta_{2}$-agonist, leukotriene antagonist, or oral corticosteroids in the previous 4 weeks, other significant medical problems, smoking history more than 20 pack years, pregnancy, or inadequate contraception in women of childbearing age.

\section{Study design}

This was a randomised, open-label, parallel group, 6month study. An independent pharmacist used computer-generated random numbers to randomise each participant to one of two groups.

Control group. Participants were provided with one budesonide inhaler containing 100 doses with $200 \mu \mathrm{g}$ budesonide per puff (Pulmicort Turbohaler ${ }^{\circledR}$
$200 \mu \mathrm{g}$, AstraZeneca), and were asked to take one puff twice daily and use their usual short-acting $\beta_{2^{-}}$ agonist as required.

Active group. Participants were provided with one combined budesonide/formoterol inhaler containing 120 doses with $200 \mu \mathrm{g}$ budesonide and $6 \mu \mathrm{g}$ formoterol per puff (Symbicort Turbohaler ${ }^{\circledR} 200 / 6 \mu \mathrm{g}$, AstraZeneca). They were asked to take one puff once daily and as required, and to use no other inhaler.

\section{Measurements}

The Mini Asthma Quality of Life Questionnaire (MiniAQLQ), ${ }^{20}$ and the Asthma Control Questionnaire $(A C Q)^{21}$ were completed by participants. The MiniAQLQ score ranges from 1 to 7, with 1 indicating severely impaired asthma-related quality of life. The ACQ score ranges from 0 to 6 , with 6 indicating severely uncontrolled asthma. Forced expiratory volume in 1 second (FEV1) and forced vital capacity (FVC) were measured with participants seated, as the best of three readings (MicroLab 3500 spirometer, Micro Medical).

\section{Protocol}

Participants were seen at their general practice for study visits. At the first visit participants completed baseline MiniAQLQ and ACQ, and underwent spirometry. Study medication was then given in exchange for the patients' usual asthma medication, with instructions on its correct use. Participants in the control group kept their usual short-acting $\beta_{2}$-agonist.

Participants were asked to contact the study coordinator to arrange a visit when their study inhaler was nearly empty. At these visits a replacement study inhaler was provided and the number of doses remaining in the returned inhaler was counted. The two asthma questionnaires were completed, information about oral steroid use or visits to their GP for asthma-related problems since the last visit were

\section{How this fits in}

Poor adherence with inhaled corticosteroid is an important problem in asthma management.

Previous approaches to improving adherence have had limited success. This study has shown that

using a single inhaler for both maintenance

treatment and symptom relief approximately

doubled the dose of inhaled corticosteroid taken.

This could be a useful strategy to overcome the

problems associated with poor adherence with

inhaled corticosteroids. 
noted, and spirometry was performed. GP records were checked to corroborate the information provided by participants about unscheduled visits. A visit was arranged at 3 months if participants had not requested a new inhaler by that time, and a final visit was scheduled at 6 months. For safety reasons, participants in the active group were asked to contact the study investigator if they used 10 or more puffs of their study inhaler in 1 day.

\section{Outcome measures}

The primary outcome was the difference between the two groups in dose of inhaled budesonide during the 6-month study period. The total dose of budesonide taken by participants was calculated by subtracting the dose of budesonide remaining in the returned inhalers from the total dose of budesonide provided. Participants' average daily dose of budesonide was obtained by dividing the total dose taken by the number of days the participant was in the study.

Secondary outcomes included the difference between the two groups for change in MiniAQLQ and $A C Q$ score, change in mean FEV1, oral corticosteroid use, and participants' visits to the GP for asthma-related problems.

Power calculations were based on the assumption that a $25 \%$ difference in the inhaled corticosteroid dose would be clinically important. Assuming an average dose of inhaled budesonide of $45 \mathrm{mg}$ (standard deviation [SD] $10 \mathrm{mg}$ ) over the 6 months in the control group, 50 patients in each group gave more than $90 \%$ power to detect a $25 \%$ difference in corticosteroid dose between the treatment groups. Due to difficulty in recruitment, only 71 participants were enrolled, but the study still had $90 \%$ power to detect this difference.

\section{Analysis}

All participants seen at least once after randomisation were included in the analysis. Daily dose of budesonide and change in FEV1, MiniAQLQ, and $A C Q$ scores were compared between groups by unpaired $t$-test. Average FEV1 over the study period was calculated as the mean of all FEV1 measurements obtained after the first visit. The number of participants who did not complete the study, and the number of participants visiting their GP or requiring oral steroids were compared using $\chi^{2}$ test. Mean and 95\% confidence intervals $(\mathrm{Cl})$ are given where appropriate.

\section{RESULTS}

Computerised records of 44 general practices were screened, from which 1961 potential participants with a diagnosis of asthma and evidence of poor
Figure 1. Flow chart showing stepwise participant selection and reasons for exclusions.

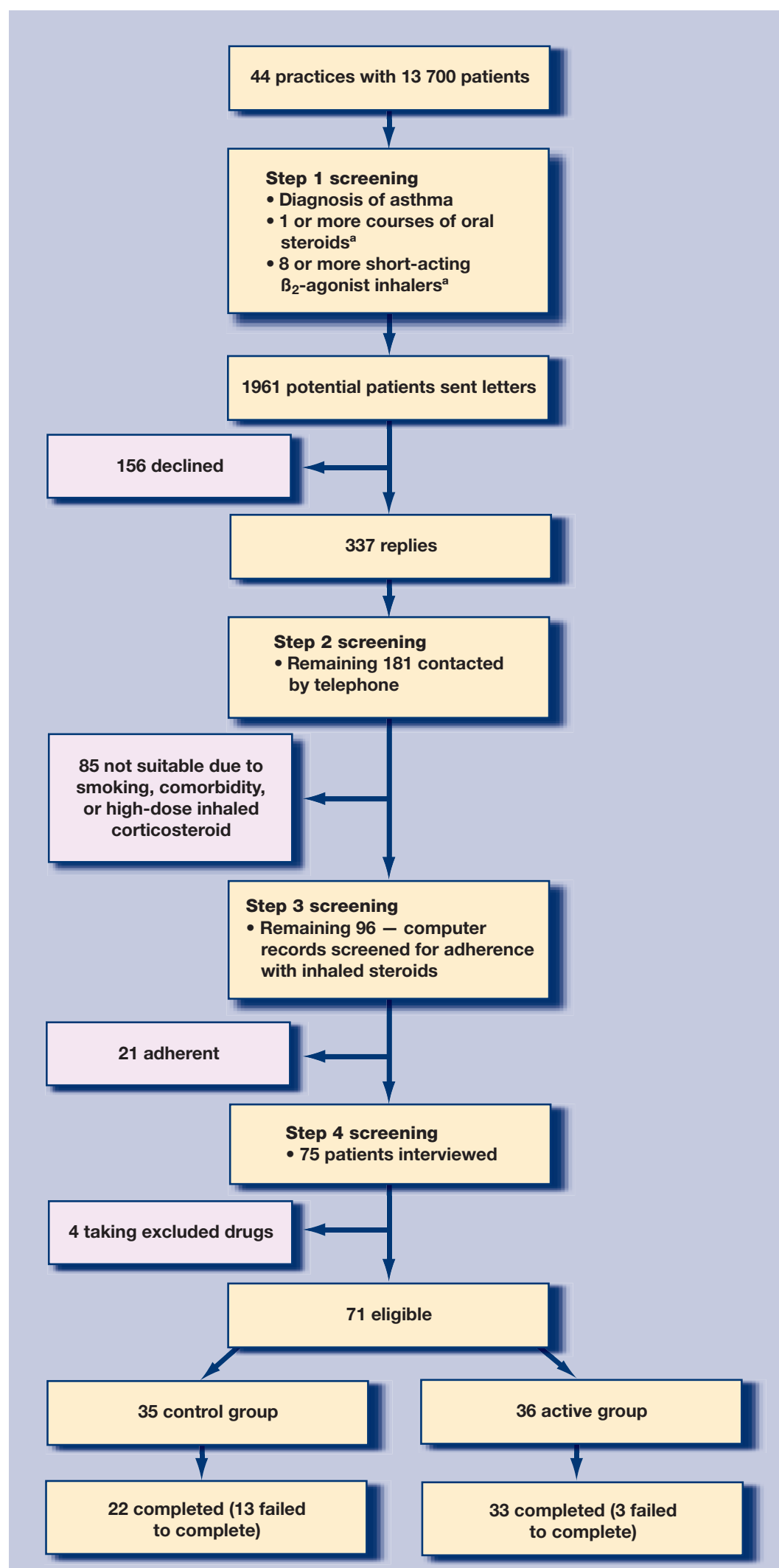

${ }^{a}$ Criteria used for step 1 screening were less stringent than eligibility criteria in case some participants had received medication from other sources. 
Table 1. Mean (SD) baseline data for control and active groups.

\begin{tabular}{lcc} 
& Control group & Active group \\
\hline Participants, $n$ & 35 & 36 \\
\hline Age, years & $40.3(12.3)$ & $40.3(12.8)$ \\
\hline Sex, male/female & $15 / 20$ & $17 / 19$ \\
\hline Duration of asthma, years & $22.6(14)$ & $23.1(12)$ \\
\hline Daily dose of ICS prescribed, $\mu \mathrm{g}^{\mathrm{a}, \mathrm{b}}$ & $565(254)$ & $611(222)$ \\
\hline Daily dose of ICS used, $\mu \mathrm{g}^{\mathrm{b}, \mathrm{c}}$ & $272(185)$ & $283(152)$ \\
\hline Adherence with ICS, \% & $45.4(16.6)$ & $45.6(17)$ \\
\hline Prednisolone courses, $n^{\mathrm{b}}$ & $1.17(1)$ & $1.0(0.9)$ \\
\hline Canisters of short-acting $\beta_{2}$-agonist, $n^{\mathrm{b}}$ & $10.2(5.3)$ & $12.4(4.9)$ \\
\hline FEV1, litres & $2.65(0.82)$ & $2.9(0.84)$ \\
\hline FEV1 \% predicted & $82.3(18.7)$ & $88.1(19.3)$ \\
\hline GP visits for asthma, $n^{\mathrm{b}}$ & $2.4(1.4)$ & $1.4(1.1)$ \\
\hline Mini AQLQ score & $4.7(0.9)$ & $4.9(1.1)$ \\
\hline ACQ score & $2.11(0.9)$ & $1.82(0.8)$ \\
\hline Smokers (previous or current), $n$ & 15 & 15 \\
\hline Pack-years among smokers & $9.5(7)$ & $6.7(5)$ \\
\hline
\end{tabular}

ICS = inhaled corticosteroid. ${ }^{\text {aDD }}$ ose of ICS equivalent to beclometasone delivered by a metered dose inhaler. ${ }^{b}$ Over the year prior to the study. 'Estimated dose of ICS taken from number of prescriptions collected.

asthma control were contacted by their GP on the researchers' behalf. A total of 181 patients were willing to participate and were screened further as

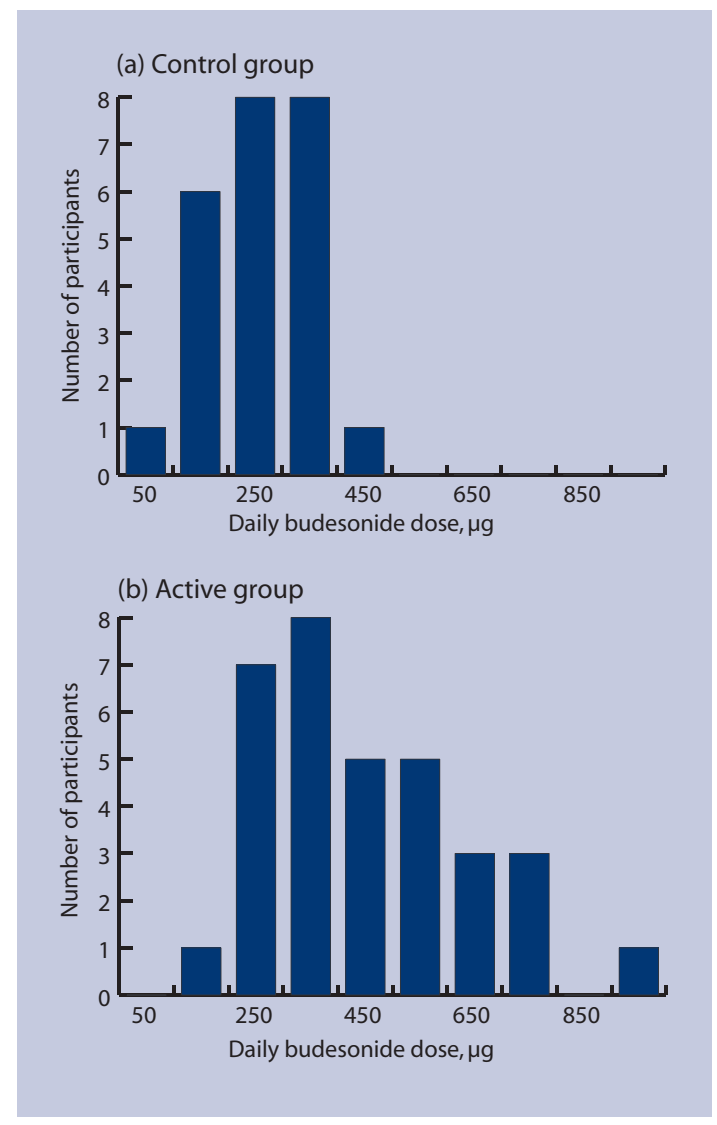

shown in Figure 1. Of these, 71 participants fulfiled the inclusion and exclusion criteria and were randomised into two reasonably well-matched groups: 35 in the control, and 36 in the active group (Table 1). Three participants from the active group and 13 from the control group withdrew from the study $(P=0.005)$. There were no outcome data for the 14 participants who failed to attend after their first visit. Of the five patients who could be contacted, reasons for discontinuing were worsening asthma (2 versus 0 ), difficulty in using the inhaler (1 versus 3 ), and sore throat (1 versus 0 ) in the control and active groups respectively; some participants gave more than one reason.

\section{Budesonide use}

The mean total dose of budesonide taken over the study period was $45.4 \mathrm{mg}(\mathrm{SD}=17 \mathrm{mg})$ and $84.1 \mathrm{mg}$ $(\mathrm{SD}=35 \mathrm{mg})$ in the control and active groups respectively. The mean daily dose in the control and active groups was therefore $252 \mu \mathrm{g}$ and $448 \mu \mathrm{g}$ respectively, giving a mean difference of $196 \mu \mathrm{g}(\mathrm{Cl}=$ 113 to 279; $P<0.001)$. The mean daily dose of budesonide ranged from $10 \mu \mathrm{g}$ to $402 \mu \mathrm{g}$ in the control group and from $143 \mu \mathrm{g}$ to $915 \mu \mathrm{g}$ in the active group (Figure 2).

Adherence with inhaled corticosteroid treatment, measured from GPs' electronic prescription records, was $43 \%$ in the year prior to the study. Adherence, measured from returned inhalers during the study, was $64 \%$ in the control group but could not be measured in the active group because participants used study medication as required.

\section{MiniAQLQ and ACQ scores}

Asthma-related quality of life and asthma control improved in both groups over the study period (Table 2). Mean increases in the MiniAQLQ score were 1.02 and 1.37 in the control and active groups respectively, giving a mean difference of $0.35(95 \%$ $\mathrm{Cl}=-0.3$ to $1.0 ; P=0.27)$. Similar trends were seen for each domain score. Mean ACQ score fell over the 6 months by 0.65 and 0.80 in the control and active groups respectively, giving a mean difference between groups of $0.15(95 \% \mathrm{Cl}=-0.5$ to $0.7 ; P=$ 0.62).

\section{FEV1}

The mean difference between baseline FEV1 and final FEV1 was $41 \mathrm{ml}$ and $55 \mathrm{ml}$ in the control and active group respectively. The mean change in FEV1 over the study period (difference between baseline FEV1 and average FEV1 for all subsequent study visits) was $52 \mathrm{ml}$ and $46 \mathrm{ml}$ in the control and active groups respectively (Appendix 1). Neither difference was significant. Average FEV1 was based on a 


\begin{tabular}{|c|c|c|c|c|}
\hline & Control group & Active group & Mean difference $(95 \% \mathrm{Cl})$ & $P$-value $\chi^{2}$ \\
\hline \multicolumn{5}{|l|}{ MiniAQLQ score ${ }^{a}$} \\
\hline Baseline & 4.8 & 4.9 & & \\
\hline Final & 5.8 & 6.3 & & \\
\hline Change & 1.02 & 1.37 & $0.35(-0.3$ to 1$)$ & $P=0.3$ \\
\hline \multicolumn{5}{|l|}{ ACQ score ${ }^{a}$} \\
\hline Baseline & 1.9 & 1.8 & & \\
\hline Final & 1.25 & 1.0 & & \\
\hline Change & -0.65 & -0.80 & $0.15(-0.5$ to 0.7$)$ & $P=0.6$ \\
\hline \multicolumn{5}{|l|}{ FEV1 (L) } \\
\hline Baseline & 2.46 & 2.86 & & \\
\hline Average & 2.51 & 2.91 & & \\
\hline Difference between baseline and average & 0.05 & 0.05 & $0.01(-0.2$ to 0.2$)$ & $P=0.9$ \\
\hline Final & 2.47 & 2.88 & & \\
\hline Difference between baseline and final FEV1 & 0.04 & 0.05 & $0.01(-0.2$ to 0.2$)$ & $P=0.9$ \\
\hline $\begin{array}{l}\text { Number of participants visiting GP/ } \\
\text { total number of GP visits }\end{array}$ & $6 / 12$ & $5 / 6$ & & $P=0.27$ \\
\hline $\begin{array}{l}\text { Number of participants prescribed oral steroids/ } \\
\text { total number of oral steroid courses }\end{array}$ & $3 / 6$ & $4 / 6$ & & $P=0.63$ \\
\hline
\end{tabular}

median of two and three visits in the control and active groups respectively.

\section{Safety}

No participant from the active group reported using 10 or more puffs a day of their study inhaler. During the study there were no hospital admissions, but six participants from the control group made a total of 12 visits to their GP for asthma-related problems, compared to five participants in the active group who had six visits. Three participants from the control group required a total of six courses of prednisolone for asthma-related problems compared to four participants and six courses in the active group. None of these differences was significant.

\section{DISCUSSION}

\section{Summary of main findings}

Participants in the control group used approximately $60 \%$ of the prescribed dose of inhaled budesonide over 6 months. Providing a single inhaler containing budesonide and formoterol for both maintenance and symptom relief almost doubled the dose of budesonide taken, thereby overcoming the problem of poor adherence seen in the control group. More participants from the active group completed the study, suggesting a preference for the single-inhaler approach.

\section{Comparison with existing literature}

Using a single inhaler containing budesonide and formoterol for maintenance and symptom relief is a new approach to managing asthma, and comparisons with conventional treatment are encouraging. To date, this approach has reduced exacerbations when compared with a higher dose of inhaled corticosteroid, ${ }^{14-16}$ or an equivalent or higher dose of a combined long-acting $\beta_{2}$-agonist and corticosteroid used for maintenance treatment only ${ }^{16-19}$ As in most studies, patients known to have poor adherence to inhaled corticosteroid treatment were excluded from participating in these studies, and reported adherence rates during the studies were high, ranging from $85-99 \%$.

Poor adherence with inhaled corticosteroids is a major problem in asthma management. It has been identified in $30 \%$ to $60 \%$ of patients, ${ }^{4-6}$ and is associated with poor asthma control, ${ }^{2}$ and increased mortality. ${ }^{22}$ Although some studies have shown that patient education can improve adherence with inhaled corticosteroids, these interventions have been labour intensive, and their implementation has had limited success overall. ${ }^{23}$ The present study found that using a single inhaler containing budesonide and formoterol for both maintenance and relief helped to overcome this problem because participants were unable to use their relief medication without inhaling a dose of budesonide.

Designing a study that does not affect adherence in the control group is difficult, because participation in any study is likely to influence behaviour and increase adherence, especially if there are regular study visits. The apparent increase in adherence in the control group (from $43 \%$ pre-study to $64 \%$ 
during the study) suggests that this may have occurred to some extent in the present study, despite attempts to minimise interventions. Nevertheless, the mean daily dose in the control group was still only $252 \mu \mathrm{g}$ (64\% of the prescribed dose), compared to $448 \mu \mathrm{g}$ for patients in the active group. Considering the evidence for poor asthma control prior to the study, a mean daily dose of $448 \mu \mathrm{g}$ would seem more appropriate than $252 \mu \mathrm{g}$, and is approximately the dose prescribed in the control group. Inhaled corticosteroid dose was chosen as the primary endpoint at this stage because clinical outcomes would have required a much larger study, and patients who rely on relief medication could have been at risk of over-treatment with the formoterol and budesonide combination. No evidence of this was found: no participant reported taking 10 or more puffs in one day, and only one patient averaged more than $800 \mu \mathrm{g}$ budesonide a day.

\section{Strengths and the limitations of the study}

Strengths of the study include the focus on patients with poor adherence and the pragmatic design. The pragmatic approach makes the study relevant to routine clinical practice but did impose some constraints on the study design. Researchers chose to compare the single inhaler approach with twicedaily budesonide, rather than budesonide and formoterol, because the study aimed to evaluate the single inhaler approach with the treatment that most poorly-adherent patients in primary care in the UK are using.

The open-label design was essential because the intervention studied was the use of one inhaler, and a double-blind study would have required participants to use two inhalers. To reduce the effect of the study on adherence in the control group, outcome measures, such as FEV1, were measured opportunistically rather than at predetermined study visits. This meant that the study reflected usual clinical practice, but also that visits occurred at different times of day and, regardless of prior bronchodilator use, reduced the ability to detect differences in secondary outcomes, particularly FEV1.

\section{Implications for future research and clinical practice}

Poor adherence with inhaled corticosteroids is common, and a major determinant of asthma morbidity. This pragmatic study demonstrates that it can be overcome by using a single inhaler for maintenance and symptom relief. A larger study to evaluate this approach on clinically important outcomes, such as exacerbations in patients with poor adherence is now required.

\section{Funding body}

The study was supported by a non-conditional grant from AstraZeneca. The sponsors of the study commented on the protocol but had no role in data collection, analysis, interpretation, or writing the paper apart from Tommy Ekström who commented on the final manuscript

\section{Ethical approval}

Nottingham City Hospital ethics committee approved the study, and all participants provided written informed consent

\section{Competing interests}

The study was conceived, designed, executed, analysed, and written up in Nottingham and was supported by a nonconditional grant from AstraZeneca which included Milind $P$ Sovani's salary. Christopher I Whale, Janet Oborne, Sue Cooper, and Kevin Mortimer have no conflict of interest. Tommy Ekström is employed by AstraZeneca. Anne $\mathrm{E}$ Tattersfield has received honoraria from AstraZeneca for speaking at meetings. Timothy $\mathrm{W}$ Harrison has received honoraria from AstraZeneca for speaking at meetings and attending advisory groups

\section{Acknowledgements}

We thank the participants, Trent Focus for helping us to contact some of the practices, Sarah Pacey (senior pharmacist) for providing randomisation codes and dispensing the study medication, and Sarah Lewis (professor in medical statistics) for statistical advice. We are especially grateful to the practices, practice managers, and IT staff for help in conducting and running the initial search and writing to the patients on our behalf

\section{Discuss this article}

Contribute and read comments about this article on the Discussion Forum: http://www.rcgp.org.uk/bjgp-discuss

\section{REFERENCES}

1. Senthilselvan A, Lawson JA, Rennie DC, Dosman JA. Regular use of corticosteroids and low use of short-acting beta2-agonists can reduce asthma hospitalisation. Chest 2005; 127(4): 242-251.

2. Krishnan JA, Riekert KA, McCoy JV, et al. Corticosteroid use after hospital discharge among high-risk adults with asthma. Am J Respir Crit Care Med 2004; 170(12): 1281-1285.

3. Williams LK, Pladevall M, Xi H, et al. Relationship between adherence to inhaled corticosteroids and poor outcomes among adults with asthma. J Allergy Clin Immunol 2004; 114(6): 1288-1293.

4. Walsh LJ, Wong CA, Cooper S, et al. Morbidity from asthma in relation to regular treatment: a community based study. Thorax 1999; 54(4): 296-300.

5. Cerveri I, Locatelli F, Zoia MC, et al. International variations in asthma treatment compliance: the results of the European Community Respiratory Health Survey (ECRHS). Eur Respir 1999; 14(2): 288-294.

6. Diette GB, Wu AW, Skinner EA, et al. Treatment patterns among adult patients with asthma: factors associated with overuse of inhaled beta-agonists and underuse of inhaled corticosteroids. Arch Intern Med 1999; 159(22): 2697-2704.

7. Boulet LP. Perception of the role and potential side effects of inhaled corticosteroids among asthmatic patients. Chest 1998; 113(3): 587-592.

8. Van der Palen J, Klein JJ, van Herwaarden CLA, et al. Multiple inhalers confuse asthma patients. Eur Respir J 1999; 14(5): 1034-1037.

9. Mann MC, Eliasson O, Patel K, ZuWallac RL. An evaluation of severity-modulated compliance with q.i.d. dosing of inhaled beclomethasone. Chest 1992; 102(5): 1342-1346.

10. Van Noord JA, Smeets JJ, Raaijmakers JA, et al. Salmeterol versus formoterol in patients with moderately severe asthma: onset and duration of action. Eur Respir J 1996; 9(8): 1684-1688.

11. Tattersfield AE, Lofdahl CG, Postma DS, et al. Comparison of formoterol and terbutaline for as-needed treatment of asthma: a randomised trial. Lancet 2001; 357: 257-261.

12. Pauwels RA, Sears MR, Campbell M, et al. Formoterol as relief medication in asthma: a worldwide safety and effectiveness trial. Eur Respir J 2003; 22(5): 787-794. 
13. Ind PW, Villasante C, Shiner RJ, et al. Safety of formoterol by Turbuhaler as reliever medication compared with terbutaline in moderate asthma. Eur Respir J 2002; 20(4): 859-866.

14. Rabe KF, Pizzichini E, Stallberg B, et al. Budesonide/formoterol in a single inhaler for maintenance and relief in mild-to-moderate asthma. Chest 2006; 129(2): 246-256.

15. Scicchitano R, Aalbers R, Ukena D, et al. Efficacy and safety of budesonide/formoterol single inhaler therapy versus a higher dose of budesonide in moderate to severe asthma. Curr Med Res Opin 2004; 20(9): 1403-1419.

16. O'Byrne PM, Bisgaard H, Godard PP, et al. Budesonide/formotero combination therapy as both maintenance and reliever medication in asthma. Am J Respir Crit Care Med 2005; 171(2): 129-136.

17. Vogelmeier C, D'Urzo A, Pauwels R, et al. Budesonide/formoterol maintenance and reliever therapy: an effective asthma treatment option? Eur Respir J 2005; 26(5): 819-828.

18. Lundborg M, Soren W, Bjermer W, et al. Maintenance plus reliever budesonide/formoterol compared with a higher maintenance dose of budesonide/formoterol plus formoterol as reliever in asthma: an efficacy and cost-effectiveness study. Curr Med Res Opin 2006; 22(5): 809-821.

19. Rabe KF, Atienza T, Magyar P, et al. Effect of budesonide in combination with formoterol for reliever therapy in asthma exacerbations: a randomised controlled, double-blind study. Lancet 2006; 368: 744-753.

20. Juniper EF, Guyatt GH, Cox FM, et al. Development and validation of the Mini Asthma Quality of Life questionnaire. Eur Respir J 1999; 14(1): 32-38.

21. Juniper EF, O'Byrne PM, Guyatt GH, et al. Development and validation of a questionnaire to measure asthma control. Eur Respir J 1999; 14(4): 902-907.

22. Suissa S, Ernst P, Benayoun S, et al. Low-dose inhaled corticosteroids and the prevention of death from asthma. $N \mathrm{Engl} \mathrm{J}$ Med 2000; 343(5): 332-336.

23. Bender B, Milgrom H, Apter A. Adherence intervention research: What have we learned and what do we do next? J Allergy Clin Immunol 2003; 112(3): 489-494. 
(a) Control group

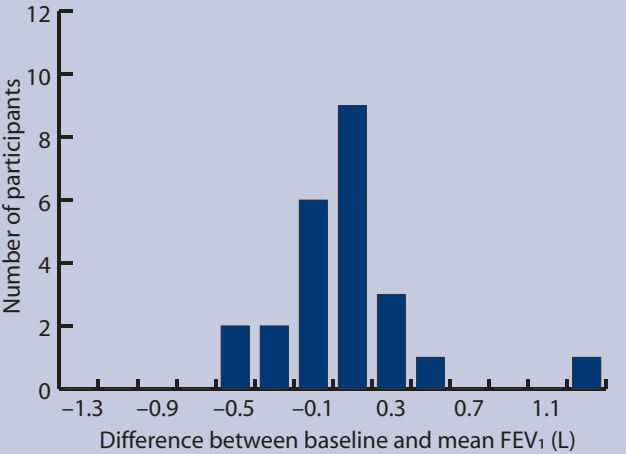

(b) Active group

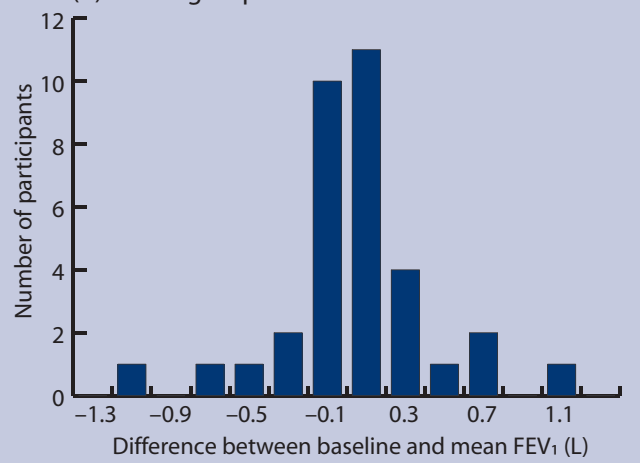

Appendix 1. Mean change in Forced expiratory volume in 1 second (FEV1) over the 6-month study period. (a) Control group; (b) active group. 